\title{
Microphysical retrievals from simultaneous polarimetric and profiling radar observations
}

\author{
M. P. Morris ${ }^{1}$, P. B. Chilson ${ }^{1}$, T. J. Schuur ${ }^{2}$, and A. Ryzhkov ${ }^{2}$ \\ ${ }^{1}$ School of Meteorology/Atmospheric Radar Research Center, Norman, OK, USA \\ ${ }^{2}$ Cooperative Institute for Mesoscale Meteorological Studies/NOAA National Severe Storms Laboratory, Norman, OK, USA
}

Received: 28 December 2008 - Revised: 6 November 2009 - Accepted: 23 November 2009 - Published: 7 December 2009

\begin{abstract}
The character of precipitation detected at the surface is the final product of many microphysical interactions in the cloud above, the combined effects of which may be characterized by the observed drop size distribution (DSD). This necessitates accurate retrieval of the DSD from remote sensing data, especially radar as it offers large areal coverage, high spatial resolution, and rigorous quality control and testing. Combined instrument observations with a UHF wind profiler, an S-band polarimetric weather radar, and a video disdrometer are analyzed for two squall line events occuring during the calendar year 2007. UHF profiler Doppler velocity spectra are used to estimate the DSD aloft, and are complemented by DSDs retrieved from an exponential model applied to polarimetric data. Ground truth is provided by the disdrometer. A complicating factor in the retrieval from UHF profiler spectra is the presence of ambient air motion, which can be corrected using the method proposed by Teshiba et al. (2009), in which a comparison between idealized Doppler spectra calculated from the DSDs retrieved from KOUN and those retrieved from contaminated wind profiler spectra is performed. It is found that DSDs measured using the distrometer at the surface and estimated using the wind profiler and polarimetric weather radar generally showed good agreement. The DSD retrievals using the wind profiler were improved when the estimates of the vertical wind were included into the analysis, thus supporting the method of Teshiba et al. (2009). Furthermore, the the study presents a method of investigating the time and height structure of DSDs.
\end{abstract}

Keywords. Meteorology and atmospheric dynamics (Precipitation; Instruments and techniques) - Radio science (Remote sensing)

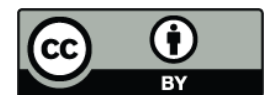

Correspondence to: P. B. Chilson (chilson@ou.edu)

\section{Introduction}

Of fundamental importance in characterizing precipitation processes from remote measurements is accurate retrieval of the underlying drop-size distribution (DSD), which is also related to other microphysical parameters such as coalescence, accretion and evaporation rate (Pruppacher and Klett, 1997). The recent application of polarimetric radar to this problem has yielded promising results for measurements at $\mathrm{S}$ band (Brandes et al., 2004), C band (Illingworth and Thompson, 2005), and X band (Gorgucci et al., 2008), as polarimetric parameters are highly dependent on the shape, and by extension the size, of sampled hydrometeors.

Similarly, wind profilers may be employed for microphysical studies as they are capable of detecting backscattered signals from turbulent variations in the atmosphere's refractive index structure function $C_{n}^{2}$ (Bragg scatter), and from falling precipitation particles (Rayleigh scatter). The DSD may be derived from the Doppler spectrum, which is a powerweighted distribution of radial velocities in the resolution volume (Doviak and Zrnic, 1993), by applying an appropriate fallspeed relationship, but this process is complicated by the presence of vertical air velocity and turbulence. A recently proposed analysis (Teshiba et al., 2009) is implemented to alleviate this issue.

A frequently occurring precipitation system in Oklahoma is the mesoscale convective system (MCS), characterized by a narrow region of intense convection along its leading edge, broad stratiform precipitation, and a transition zone that separates these two regimes (Smull and Houze, 1987). The large temporal and spatial scales of such systems often results in significant precipitation accumulations in affected areas. Microphysical processes responsible for rain formation in the different regimes have a profound impact on the distribution and intensity of rainfall at the surface. Furthermore, stormscale circulations can affect the hydrometeor species aloft, which impacts the development of the precipitation as it

Published by Copernicus Publications on behalf of the European Geosciences Union. 
nears the surface. Additionally, these systems provide an excellent opportunity to observe rain microphysics in both convective and stratiform type precipitation environments and quantify errors in the retrieval process inherent to individual precipitation regimes.

The remainder of this paper focuses on the application of combined dual-polarimetric weather radar and wind wind profiler observations of precipitation associated with MCS conditions. A brief introduction of the radar systems is first presented along with an outline of the method described in (Teshiba et al., 2009) for combining these data sets in order to retrieve information pertaining to the properties of the precipitation and the environment in which it is observed. The present study extends the work of Teshiba et al. (2009) and places a greater emphasis on the investigation of precipitation microphysics. Next data collected during two MCS events occurring in Oklahoma are analyzed. The two cases were specifically chosen to illustrate the effect of different radar scanning strategies on the retrieval algorithms discussed. Finally a summary of the findings is presented.

\section{Observational techniques}

In collaboration with the NOAA National Severe Storms Laboratory, the University of Oklahoma's Atmospheric Radar Research Center (ARRC) has installed a suite of remote sensing and in-situ measurement systems in central Oklahoma to better understand the microphysical processes responsible for rain formation. These include a UHF wind profiler (ARRC profiler) and a Joanneum Research twodimensional video disdrometer (2DVD), which can be used in conjunction with the prototype polarimetric WSR-88D (hereafter referred to as KOUN). Since 2005, the ARRC profiler and 2DVD have been deployed at the University of Oklahoma's Kessler Farm Field Laboratory (KFFL), a remote instrumentation site located $28.5 \mathrm{~km}$ south of KOUN (Chilson et al., 2007) that has been used in conjunction with various related precipitation studies in the Norman meteorological community. Additionally, the separation between KFFL and KOUN is such that the resolution volumes of the two radars are of approximately the same size at lower altitudes. When sampling at a height of about $600 \mathrm{~m}$ above KFFL and for the radar configurations used during the experiments presented here, the radial and transverse resolutions of the ARRC profiler are about $200 \mathrm{~m}$ and $100 \mathrm{~m}$, respectively. The radial and transverse resolutions of KOUN when probing the same region of space are $250 \mathrm{~m}$ and $500 \mathrm{~m}$, respectively.

\subsection{UHF wind profiler}

The ARRC profiler is a UHF $(\lambda=32.79 \mathrm{~cm})$ wind profiling radar, also classified as a boundary-layer radar (BLR) as it is designed to operate to a maximum height of about $3 \mathrm{~km}$
Table 1. Typical operating parameters of the ARRC profiler.

\begin{tabular}{lc}
\hline Parameter & Value \\
\hline Wavelength $\lambda(\mathrm{cm})$ & 32.79 \\
Frequency $f(\mathrm{MHz})$ & 915 \\
Range resolution $\delta r(\mathrm{~m})$ & 210 \\
Pulse width $\tau(\mu \mathrm{s})$ & 1.4 \\
Beamwidth (degrees) & 9 \\
FFT points & 128 \\
Coherent integrations & 100 \\
Dwell time $(\mathrm{s})$ & 24 \\
Peak power $(\mathrm{W})$ & $\sim 600$ \\
\hline
\end{tabular}

in clear air. Table 1 lists the typical operating parameters for the ARRC profiler for the observations presented here. The profiler uses a phased-array microstrip antenna capable of electronically beam steering in up to 5 directions (Carter et al., 1995), though during the precipitation events discussed below the profiler was operated solely in a vertical mode to allow maximum microphysical data to be obtained. That is, the profiler was used to sample the atmosphere along regularly spaced sampling volumes (or range gates) in height. Due to the relatively long wavelength of the transmitted radio waves, even the largest raindrops will scatter in the Rayleigh regime. Pruppacher and Beard (1970) note that drops with diameters greater than $10 \mathrm{~mm}$ tend to break up, imposing a practical limit on the size of the falling raindrops. For a drop of this size, the ratio $D / \lambda$ is only about 0.03 and it is assumed that the backscattering cross section $\sigma_{b}$ is proportional to the sixth power of the diameter (Battan, 1973), allowing for direct retrieval of the drop size distribution from UHF Doppler velocity spectra (Balsley and Gage, 1982).

The radar reflectivity factor $Z\left(\mathrm{~mm}^{6} \mathrm{~m}^{-3}\right)$ is proportional to the sixth power of the diameters of illuminated raindrops, expressed by (Doviak and Zrnic, 1993):

$Z=\int_{0}^{\infty} D^{6} N(D) d D$

in which $N(D)\left(\mathrm{mm}^{-1} \mathrm{~m}^{-3}\right)$ is the total number of drops per unit volume with diameters (mm) between $D$ and $D+d D$. Under the assumption that the resolution volume is completely filled with liquid raindrops of sufficiently small size that the Rayleigh scatter assumption is valid and the effects of noise have been removed, the total backscattered power at the reciever from a resolution volume at range $r(\mathrm{~m})$ can be expressed in terms of $Z$ as

$P(r)=C \frac{Z}{l^{2} r^{2}}$

where $l$ is a unitless loss factor due to attenuation by precipitation and atmospheric gases, and $C$ is a constant related to various physical parameters of the radar hardware and choice of operating parameters. Alternatively, the returned power 
may be expressed in terms of the Doppler spectrum $S(v)$, a power-weighted distribution of radial velocities inside the resolution volume (Doviak and Zrnic, 1993) as

$P(r)=\int_{-\infty}^{\infty} S(v) d v$

$S(v)$ is the energy backscattered by targets with radial velocities $\left(\mathrm{m} \mathrm{s}^{-1}\right)$ between $v$ and $v+d v$. Assuming the loss factor $l$ to be constant across the range of fallspeeds and accounting for range and calibration effects, Eqs. (2) and (3) define a closed form expression for the returned power in terms of both the drop size distribution and the Doppler spectrum. The two may be equated, yielding an expression for the drop size distribution:

$N(D)=\frac{S_{r c}(v)}{D^{6}} \frac{d v}{d D}$.

using the notation that $S_{r c}(v)$ is the calibrated, rangecorrected Doppler spectrum, $D(\mathrm{~mm})$ is the raindrop diameter, and $d v / d D\left(\mathrm{~m} \mathrm{~s}^{-1} \mathrm{~mm}^{-1}\right)$ represents the coordinate transformation from velocity space to diameter space and is derived from the fallspeed relation, first proposed by Brandes et al. (2002):

$$
\begin{array}{r}
v(D)=-0.1021+4.392 D-0.9551 D^{2}+ \\
0.07934 D^{3}-0.002362 D^{4}
\end{array}
$$

in which $v(D)$ is the terminal velocity $\left(\mathrm{m} \mathrm{s}^{-1}\right)$ of a raindrop with diameter $D(\mathrm{~mm})$. A density correction factor of $\left(\rho_{0} / \rho\right)^{0.4}$ may be appended to the above relationship to account for the vertical decrease of air density in the standard atmosphere, where $\rho$ and $\rho_{0}\left(\mathrm{~kg} \mathrm{~m}^{-3}\right)$ are the densities aloft and at the surface, respectively (Foote and duToit, 1969). The vertical density structure may easily be calculated from a nearby representative radiosonde observation. In the case of the events presented in the current work, the 12:00 UTC soundings from the Norman National Weather Service Office were utilized.

\subsection{KOUN}

As part of the ongoing effort to modernize the United States weather agencies and realizing the need for ongoing research, the National Weather Service provided the components necessary for assembly of a research WSR88D under the care of the National Severe Storms Laboratory (NSSL), to be used for developing advanced radar techniques and advancing operations (Doviak et al., 2000). The KOUN radar is an S-Band $(\lambda=10.9 \mathrm{~cm})$ dual-linearpolarization weather radar that simultaneously transmits vertically and horizontally-polarized radio waves. It has been used extensively for the development of methods to improve acquisition time, reduce range and velocity ambiguity (Sachidananda and Zrnic, 2006), identify polarimetric signatures in supercell thunderstorms (Kumjian and Ryzhkov, 2008; Ryzhkov et al., 2005b), and improve quantitative
Table 2. Typical operating parameters of the KOUN polarimetric radar.

\begin{tabular}{lc}
\hline Parameter & Value \\
\hline Wavelength $\lambda(\mathrm{cm})$ & 10.9 \\
Aliasing velocity $V_{a}\left(\mathrm{~m} \mathrm{~s}^{-1}\right)$ & 27.595 \\
Aliasing range $r_{a}(\mathrm{~km})$ & 150 \\
Pulse repetition frequency $(\mathrm{Hz})$ & 1012 \\
Pulse width $\tau(\mu \mathrm{s})$ & 1.5 \\
Beamwidth (degrees) & 1 \\
Peak power (Watts) & 750000 \\
\hline
\end{tabular}

precipitation estimation during periods of intense rainfall (Ryzhkov et al., 2005a). The success of this radar has prompted the NOAA officials to upgrade the national WSR88D network to include polarimetric capability (Saffle et al., 2007). Typical operating parameters for KOUN during precipitation events are listed in Table 2.

Polarimetric radar is capable of retrieving the DSD parameters of an assumed functional form of the DSD due to its sensitivity to both size and shape effects. Numerous methods have been proposed in the literature (Seliga and Bringi, 1978; Zhang et al., 2001; Cao et al., 2007) to retrieve parameters of an exponential or gamma raindrop distribution. Here, we fit polarimetric data to the two-parameter exponential DSD model: (Laws and Parsons, 1943):

$N(D)=N_{0} \exp (-\Lambda D)$,

where $N_{0}$ is a concentration parameter $\left(\mathrm{mm}^{-1} \mathrm{~m}^{-3}\right)$ and $\Lambda$ is a slope parameter $\left(\mathrm{mm}^{-1}\right)$. Implications of using the exponential DSD can be found in Zhang et al. (2006, 2008); Cao et al. (2007). The $n$-th moment $M_{n}$ of the exponential DSD is given by:

$M_{n}=N_{0} \Gamma(n+1) \Lambda^{-(n+1)}$,

where $\Gamma(\cdot)$ denotes the complete gamma function. Taking the ratio of any two moments eliminates $N_{0}$, and gives $\Lambda$ in terms of this ratio. Given the value of $\Lambda, N_{0}$ can then be calculated from any moment.

Seliga and Bringi (1976) propose a method to retrieve the two parameters of the exponential DSD of the form

$N(D)=N_{0} \exp \left(\frac{-3.67 D}{D_{0}}\right)$

from $Z_{H}\left(\mathrm{~mm}^{6} \mathrm{~m}^{-3}\right)$ and $Z_{D R}(\mathrm{~dB})$ measured at $\mathrm{S}$ band, based on the Gans (1912) extension to the classical Rayleigh scatter theory. Here $D_{0}$ is the median volume diameter given by

$$
\int_{0}^{D_{0}} D^{3} N(D) d D=\frac{1}{2} \int_{0}^{\infty} D^{3} N(D) d D .
$$


The radar reflectivity factor $Z_{H V}$ at horizontal or vertical polarization may be expressed as

$Z_{H V}=\frac{\lambda^{4} 10^{6}}{\pi^{5}|K|^{2}} \int_{0}^{D_{\max }} \sigma_{H V}(D) N(D) d D$,

where $\sigma_{H V}\left(\mathrm{~cm}^{2}\right)$ is the backscattering cross section at horizontal or vertical polarization, $\lambda(\mathrm{cm})$ is the radar wavelength, $|K|$ (unitless) is the dielectric constant of liquid water, $D$ is the drop diameter $(\mathrm{cm}), D_{\max }$ is set to $1 \mathrm{~cm}$, and the factor of $10^{6}$ converts $Z_{H V}$ to $\mathrm{mm}^{6} \mathrm{~m}^{-3}$. Differential reflectivity $Z_{D R}(\mathrm{~dB})$ is given by

$Z_{D R}=10 \log _{10} \frac{Z_{H}}{Z_{V}}$,

in which $Z_{H}$ and $Z_{V}\left(\mathrm{~mm}^{6} \mathrm{~m}^{-3}\right)$ are the radar reflectivity factors at horizontal and vertical polarizations, respectively. From Eqs. (8-11), $D_{0}$ can be calculated through substitution of Eq. (10) into Eq. (11), and $N_{0}$ may be solved from Eq. (10) given $D_{0}$.

In addition to the differential reflectivity $Z_{D R}$, values of correlation coefficient $\rho_{H V}$ are considered in this study. The value of $\rho_{H V}$ expresses the degree to which the average backscattered horizontal and vertical returns are correlated. The correlation coefficient is often used as a discriminator when classifying precipitation by type, e.g., liquid phase or frozen phase or when identifying sources of noise in dualpolarimetric radar data (Ryzhkov et al., 2005a).

\subsection{DVD}

Since rain microphysics are retrieved from the two radars based on remote sensing data, it is important to provide ground truth to these measurements to increase confidence in their accuracy. The 2DVD provides such a capability by directly sampling falling hydrometeors as they pass through a pair of parallel light sheets, casting shadows onto a pair of orthogonally-viewing line-scan cameras. The orthogonal views allow the 2DVD software to determine the axial ratio, oblateness, and equivalent diameter of each drop, and the time delay between the drop passing through the two sheets gives the fallspeed. The 2DVD records this information along with an image of the drop from the two cameras. The cameras on which the shadows are projected are of finite size, so the DSD measured by the 2DVD is discretized instead of continuous. The minimum drop diameter the instrument can resolve is $0.19 \mathrm{~mm}$. During the post-processing of the raw data, sampled drops are partitioned into $41 \mathrm{di}-$ ameter bins of $0.2 \mathrm{~mm}$ width between 0.1 and $8.1 \mathrm{~mm}$, and DSD data are provided at 1 min intervals. A more complete description of the 2DVD system is given by Kruger and Krajewski (2002). Fitting of the observed DSD to a model may be achieved either through a least-squares process or by a moment method as described above.

\subsection{Retrieval comparison}

To assess the relative accuracy of the DSD retrieval methods and quantify the differences between precipitation regimes, radar reflectivity factor $Z$, mass-weighted mean diameter $D_{m}$, and rainfall rate $R$ are calculated from the data collected by each instrument and compared. Vertical profiles of the polarimetric and DSD data from KOUN are extracted from the RHI or PPI scans and interpolated onto a grid that matches the range gate spacing of the wind profiler (Teshiba et al., 2009). For the data presented in this study, wind profiler and KOUN data from the third range gate above the profiler $(600 \mathrm{~m}$ a.g.l.) are presented due to a signal processing error that corrupted data at the lowest two range gates. Comparison of radar data from the lowest possible elevation and the 2DVD ensures the proper behavior of the retrievals, increasing the confidence in the retrievals at greater altitudes.

Direct comparison between the retrieved exponential DSDs is made using the mass-weighted mean diameter $D_{m}$ $(\mathrm{mm})$, which in terms of an exponential distribution is expressed (using Eq. 7) as

$D_{m}=\frac{M_{4}}{M_{3}}=\frac{N_{0} \Gamma(5) \Lambda^{-5}}{N_{0} \Gamma(4) \Lambda^{-4}}=\frac{4}{\Lambda}$.

Here, $D_{m}$ is selected as it is inversely proportional to the slope parameter $\Lambda$ and its behavior is much more intuitive physically.

\subsection{Vertical velocity estimation}

One of the complications that arises in the retrieval of the raindrop size distribution from wind profiler Doppler spectra is the bias which is introduced in the presence of vertical air motion (Rogers, 1967). Previous investigators (Wakasugi et al., 1986; Cifelli et al., 2000; Schafer et al., 2002) have utilized combined UHF and VHF wind profiler data to deconvolve the Bragg scattering portion of the observed Doppler spectrum under the simplifying assumption of Gaussian turbulence (Tennekes and Lumley, 1973). Here, we utilize a method first proposed by Teshiba et al. (2009) in which the fallspeed relation given by Eq. (5) is applied to the retrieved DSD from polarimetric parameters and compared to that measured by the UHF profiler. The first moments $\left(\bar{v}_{r}\right)$ of both spectra are calculated and the difference between them is attributed to vertical air motion. The UHF Doppler spectra are then corrected and the DSD is retrieved. Figure 1 graphically depicts the retrieval process and interdependency between the data collected by the instruments. Preliminary studies of this method (Morris et al., 2008; Morris, 2008) applied to MCS events in Oklahoma indicate the algorithm is robust and produces results consistent with idealized models of such storms. 


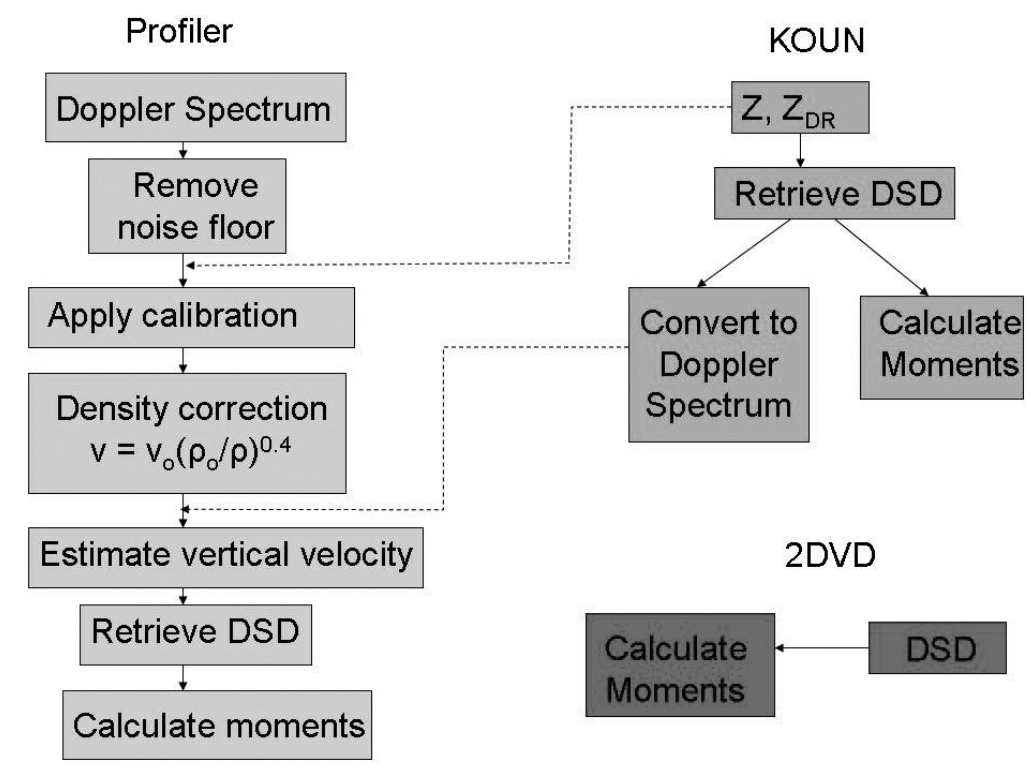

Fig. 1. Flowchart demonstrating the retrieval process from various instruments.

\section{Case study - 11 March 2007}

On the morning of 11 March 2007, a mature squall line impacted much of central Oklahoma and presented an opportunity to examine its microphysical structure with the combined instrumentation. During this event, KOUN collected polarimetric data in a range-height indicator (RHI) mode above KFFL, while the ARRC profiler and 2DVD provided continuous data for the duration of the event. A total of $38 \mathrm{~mm}$ of precipitation was recorded by the Oklahoma Mesonet installation at Washington, located about $320 \mathrm{~m}$ south-southeast of the ARRC profiler. The structure of the squall line also allowed for testing of the DSD and vertical velocity retrieval algorithms in convective and stratiform precipitation cases.

The 11 March 2007 squall line did not exhibit classic squall line structure, as the stratiform precipitation in the rear of the system was not expansive and the presence of a mesoscale convective vortex resulted in north-south asymmetry (Houze, 1993). However, the extent of the stratiform precipitation was sufficient to gather a significant amount of data from KOUN, the ARRC profiler, and the 2DVD. Range-time-intensity (RTI) plots displaying various parameters measured by the ARRC profiler and KOUN during the duration of the event are provided in Fig. 2. The leading edge of the convection can be seen as a region of enhanced signalto-noise ratio (SNR) from approximately 11:00 to just after 11:30 UTC and extending above $6 \mathrm{~km}$ in height. Significant velocity aliasing resulting from intense updrafts can be seen around 11:30 UTC. The polarimetric variables presented in the figure $\left(Z_{H}, Z_{D R}\right.$, and $\left.\rho_{H V}\right)$ are consistent with the measurements from the profiler, as large reflectivity values near the surface are indicative of heavy precipitation cores. En- hanced $Z_{D R}$ values near the surface indicate the presence of large drops, which tend to be more frequent in convective clouds due to strong vertical motion and rapid growth near the cloud base (Tokay and Short, 1996). Estimates of the vertical air motion within the precipitation region are presented in Teshiba et al. (2009).

Behind the leading convection, average vertical velocity decreases as precipitation particles travel through the transition zone to the stratiform region, while SNR measured by the ARRC profiler decreases as a result of the decrease in intensity of precipitation. This region corresponds to the time interval from just after 11:30 till just before 12:00 UTC. An associated decrease in $Z_{H}$ and $Z_{D R}$ measured by KOUN indicates this is a classic transition zone. A second region of enhanced SNR and vertical velocity is observed behind this transition zone at about 11:45 UTC, coincident with a downward depression in the $\rho_{H V}$ field and enhanced $Z_{D R}$ near $2 \mathrm{~km}$ a.g.l., which may be caused by compensatory subsidence in the wake of the intense leading convection, and consistent with the results presented by Smull and Houze (1987) and Houze and Rappaport (1984). Again, the reader is referred to Teshiba et al. (2009) for estimates of the vertical air motion within the precipitation region.

In the trailing stratiform region of the squall line, the melting layer is clearly evident from the strong fallspeed gradient at around $2.5 \mathrm{~km}$ a.g.1., its height consistent with the $0^{\circ} \mathrm{C}$ isotherm from the 12:00 UTC Norman sounding. In the figure this region corresponds to the period just before 12:00 through 14:30 UTC. The radar bright band is also clearly evident in the $Z_{H}$ values measured by KOUN, indicating the rapid melting of snowflakes. A well-defined region of decreased $\rho_{H V}$ between 2.5 and $3 \mathrm{~km}$ a.g.l. indicates the 

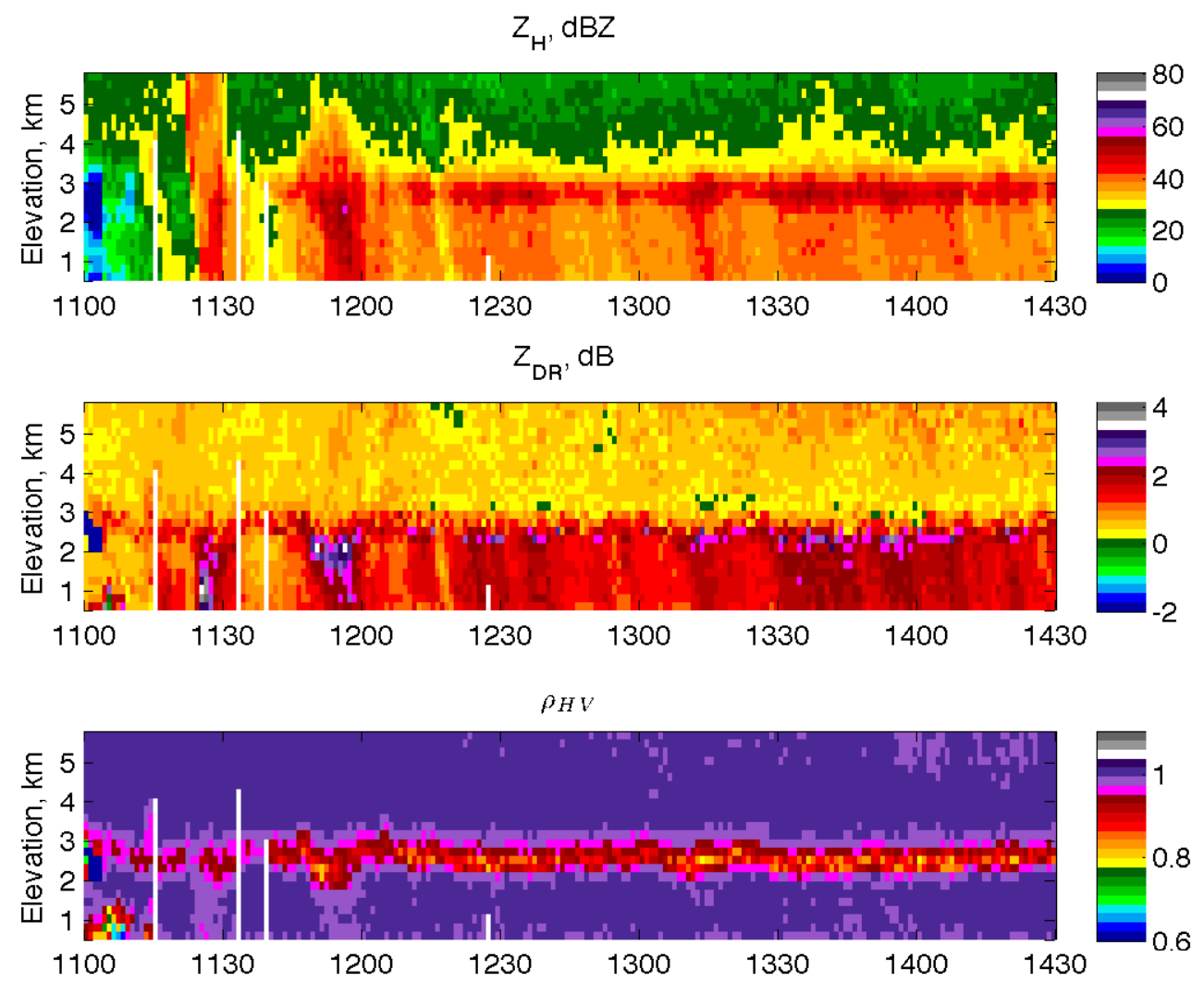

$S N R, d B$

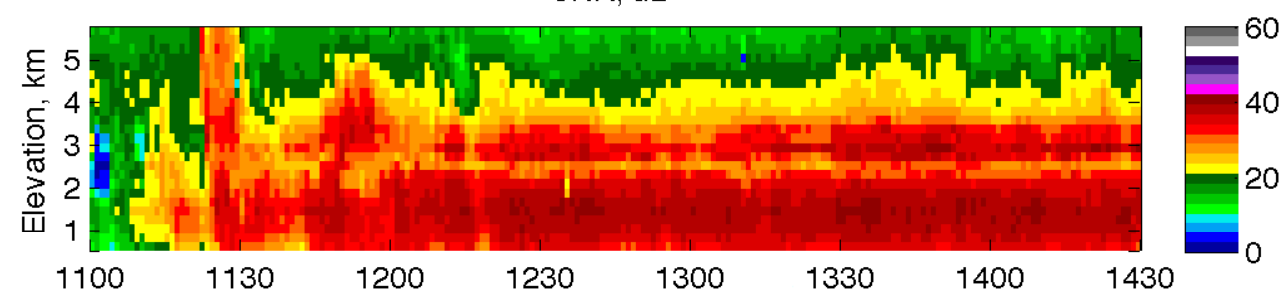

Radial Velocity, $\mathrm{m} \mathrm{s}^{-1}$

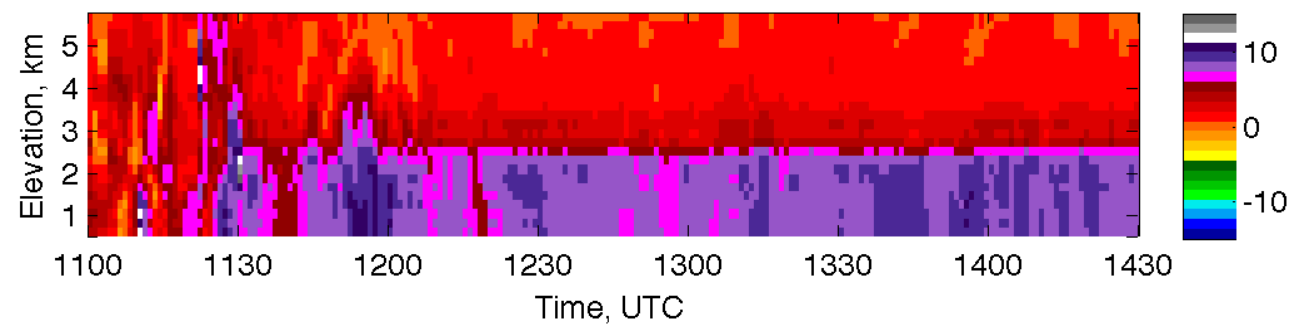

Fig. 2. Time-height cross sections of data collected during 11 March 2007 squall line event. Elevation is in kilometers above ground level, time is in UTC. Presented data fields are (from top to bottom): KOUN $Z_{H}$ (dBZ), KOUN $Z_{D R}$ (dB), KOUN $\rho_{H V}$, ARRC profiler signal-to-noise ratio $(\mathrm{dB})$, and ARRC profiler mean vertical velocity $\left(\mathrm{m} \mathrm{s}^{-1}\right)$.

presence of mixed-phase particles in the melting layer, and intermittent regions of enhanced $Z_{D R}$ may be indicative of itermittent periods of heavy (large $Z_{D R}$ ) and light (small $\left.Z_{D R}\right)$ precipitation.

\subsection{DSD parameters}

A time history of $Z, D_{m}$, and $R$ for the 11 March 2007 event is presented in Fig. 3. Data from KOUN, the 2DVD, and the ARRC profiler are plotted together for comparison. Profiler 

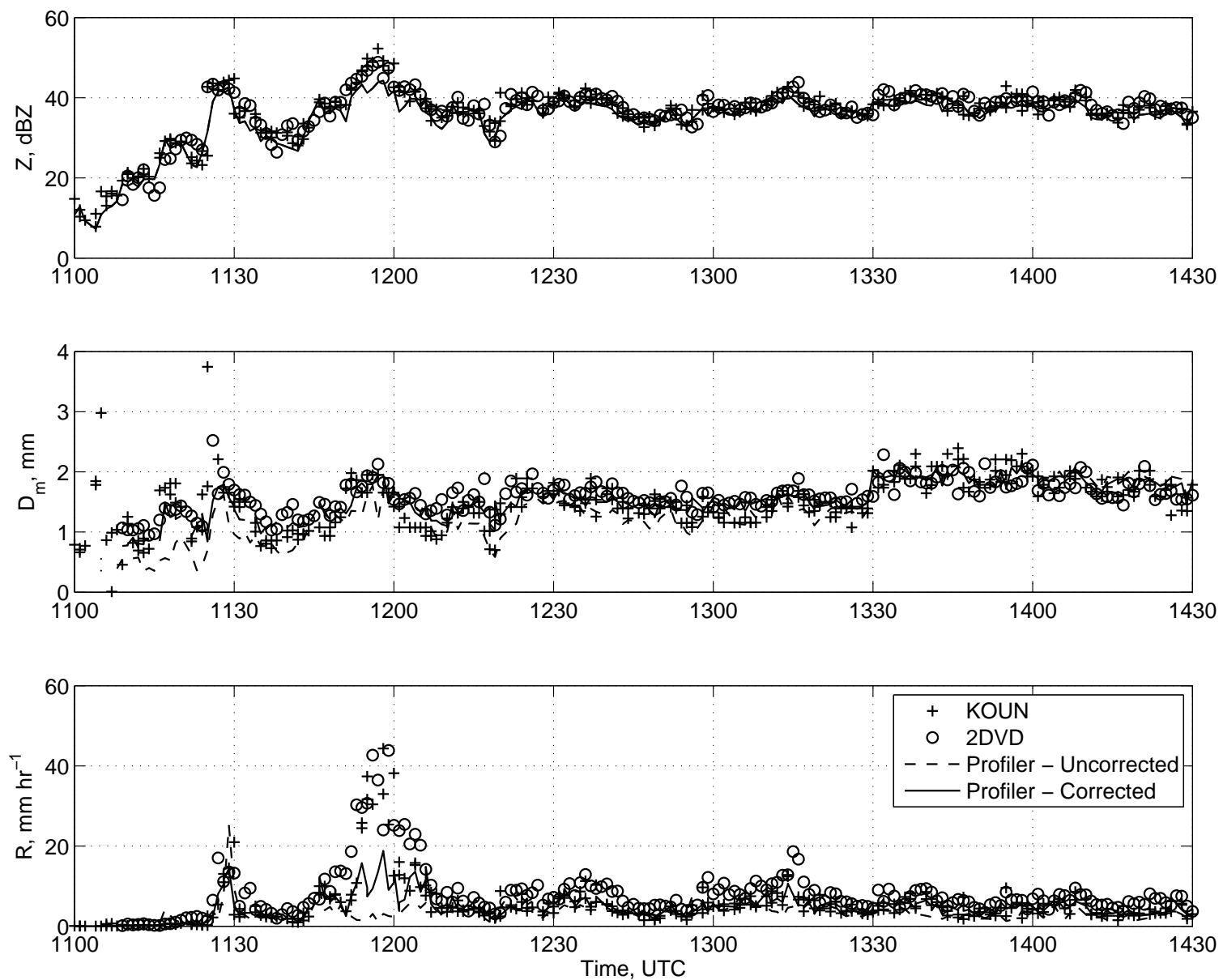

Fig. 3. Time histories of $Z, D_{m}$, and $R$ for data collected during the 11 March 2007 rain event. The 2DVD data were collected at the surface and the radar data correspond to a height of $600 \mathrm{~m}$ a.g.l.

data with and without the vertical air velocity correction applied are plotted to illustrate the improvement in the retrieval from the Doppler spectra. DSD data from the profiler and KOUN are from the third gate above ground level $(\sim 600 \mathrm{~m})$ and the 2DVD data are recorded at the surface.

Both KOUN and the ARRC profiler are independently calibrated. The radar reflectivity factor $Z$ for KOUN is matched to those reported for the operational WSR-88D system KTLX. In addition to the standard $Z$ calibration, KOUN additionally requires a $Z_{D R}$ calibration. This is achieved by requiring that $Z_{D R}$ values obtained immediately above the bright band have a value of 0.2 to 0.3 , which is characterisitic of the $Z_{D R}$ of the dry aggregated snow that is typically found in that region. The wind profiler has been calibrated using the 2DVD during a period of precipitation. Bearing this in mind, the $Z$ values from each instrument agree rather well (see the upper panel of Fig. 3). Gage et al. (2000) have proposed that wind profilers be used to independently calibrate scanning radars for combined instrument studies, and the data shown in Fig. 3 support this claim. Were the $Z$ values to be in considerable disagreement, the mathematical ba- sis for the conversion from velocity space to diameter space would be erroneous and some of the subsequent data would be of little value.

The different retrieved time histories of $D_{m}$ shown in Fig. 3 generally show good agreement; although, some deviations do exist. For example, prior to $\sim 13: 30$ UTC, the values of $D_{m}$ calculated using the retrieved DSDs from KOUN and the profiler are slightly lower than those from the 2DVD. After $\sim 13: 30$ UTC, the agreement in the estimates of $D_{m}$ and $R$ tend to improve. Interestingly, a discrete jump can be seen in the time history of $D_{m}$ observations at about this time. This can be attributed to the increased presence of embedded showers in the stratiform rain characterized by fewer observed small drops. Although not well documented in the literature, the trailing precipitation associated with MCSs observed in Oklahoma are known to be non-uniform. It is not clear at this point if these two features in the data are related to one another or not. Some of the fluctuations in $D_{m}$ retrieved prior to $\sim 11: 25 \mathrm{UTC}$ are possibly the result of weak signal-to-noise ratio (Fig. 2). 

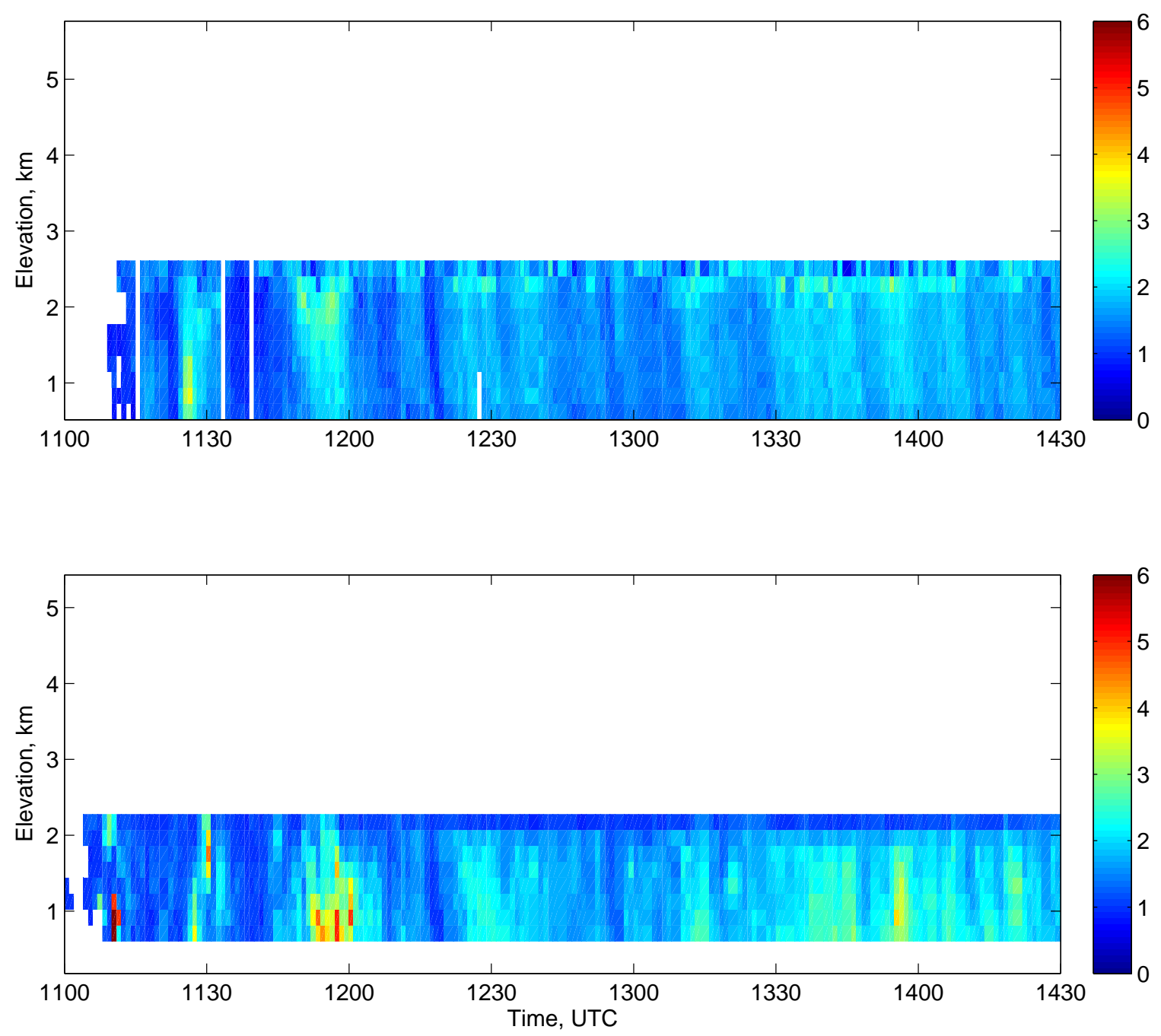

Fig. 4. RTI plots of $D_{m}$ for an exponential DSD retrieved from KOUN (upper panel) and the ARRC profiler (lower panel) during 11 March 2007 rain event. Units are in $\mathrm{mm}$. Data above the melting layer not presented.

Rainfall rate data shown in Fig. 3 are an indication of the improvement of the profiler DSD retrieval algorithm when the vertical velocity algorithm is applied. During the leading convection, strong upward air motion is present even though the rain rate is rather low. The uncorrected profiler spectrum yields a maximum rain rate in excess of $20 \mathrm{~mm} \mathrm{~h}^{-1}$, while the other three data sources agree that the actual rain rate is closer to $15 \mathrm{~mm} \mathrm{~h}^{-1}$. Furthermore, improvement is more noticeable during an intense downdraft observed near 12:00 UTC. Without the vertical velocity correction, the downward transport of hydrometeors is not detected by the ARRC profiler, so it yields rain rates less than $10 \mathrm{~mm} \mathrm{~h}^{-1}$ while the corrected data produce rates of $15-20 \mathrm{~mm} \mathrm{~h}^{-1}$. However, the 2DVD and KOUN data present rain rates in excess of $20 \mathrm{~mm} \mathrm{~h}^{-1}$, and as high as $40 \mathrm{~mm} \mathrm{~h}^{-1}$. Teshiba et al. (2009) speculate that in this region melting graupel and small hail above the melting layer generates additional neg- ative buoyancy, accelerating the growth of descending raindrops. In the stratiform region of the MCS, the vertical air motion is negligible and the retrieved rain rates are in good agreement between each of the instruments.

Table 3 lists the total rainfall accumulations measured by the ARRC profiler, KOUN, the 2DVD and the Oklahoma Mesonet site at Washington for the interval 11:15 UTC to 14:48 UTC 11 March 2007. It is clear that the vertical velocity correction improves the profiler-based rainfall accumulation, as the corrected value is within $2.5 \mathrm{~mm}$ of the Mesonet observation, while the uncorrected data produce less than $20 \mathrm{~mm}$ of total precipitation. Both KOUN and the disdrometer slightly overestimate the rainfall rate, but this may be a result of the relative sampling times of each instrument (1 min for KOUN and the 2DVD, 5 min for the Mesonet).

Time-height plots of the mass-weighted mean diameter $D_{m}$ for a fitted exponential distribution and the associated 

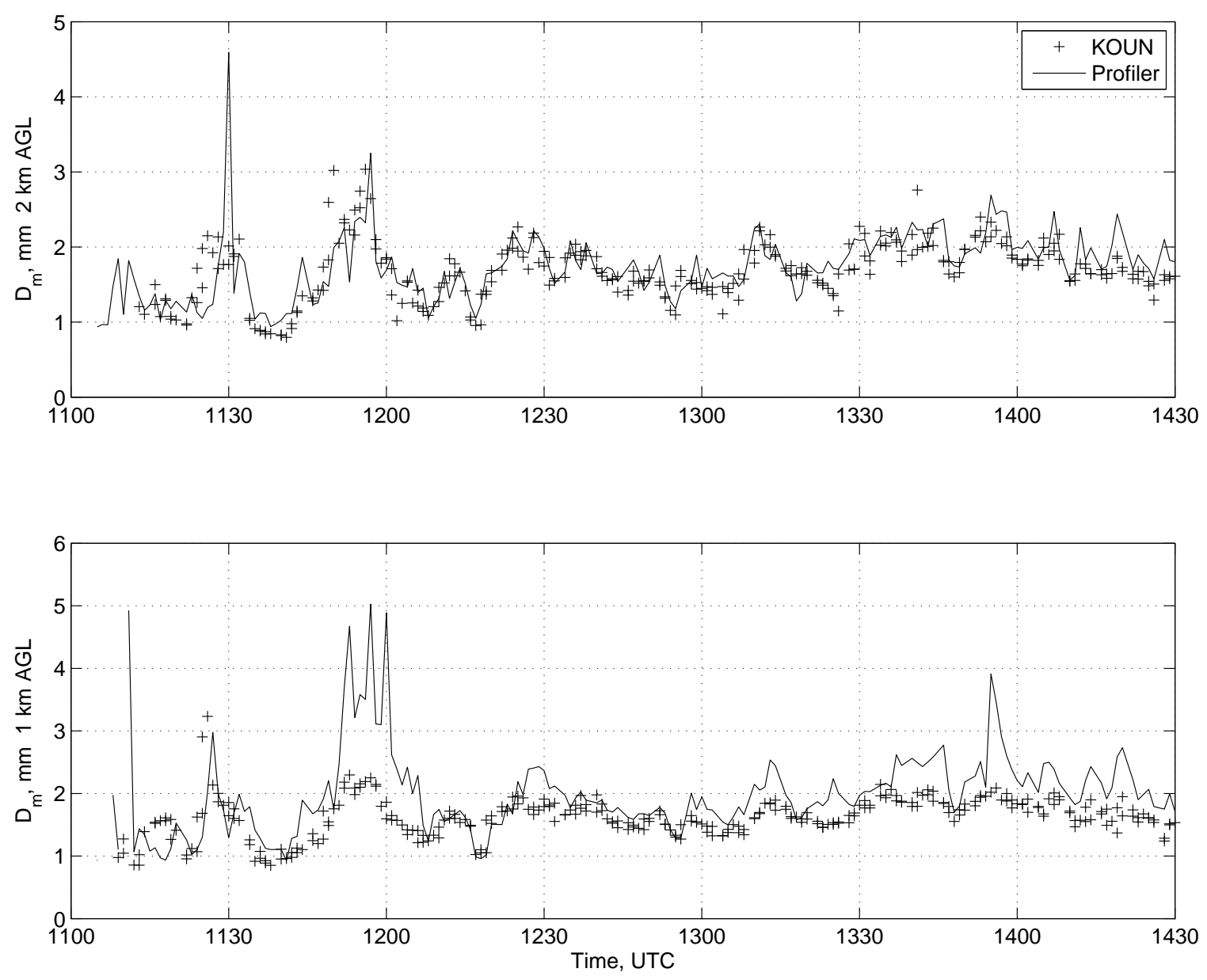

Fig. 5. Time history plots of $D_{m}$ for an exponential DSD retrieved from KOUN and the ARRC profiler during 11 March 2007 rain event at $2 \mathrm{~km}$ a.g.l. (upper panel) and $1 \mathrm{~km}$ a.g.l. (lower panel).

Table 3. Total rainfall accumulations for the 11 March 2007 event.

\begin{tabular}{lc}
\hline Instrument & Total rainfall \\
\hline Oklahoma Mesonet & $27.69 \mathrm{~mm}$ \\
KOUN & $30.16 \mathrm{~mm}$ \\
Profiler - uncorrected & $19.3 \mathrm{~mm}$ \\
Profiler - corrected & $25.2 \mathrm{~mm}$ \\
2DVD & $29.36 \mathrm{~mm}$ \\
\hline
\end{tabular}

time histories at 1 and $2 \mathrm{~km}$ a.g.l. are shown in Figs. 4 and 5, respectively. These representations of the data are not only useful for investigating time and height variations of $D_{m}$, but also for identifying areas of departure between the different estimates (from KOUN, the ARRC profiler, and the 2DVD). For example, as seen in Figs. 4 and 5 just prior to 12:00 UTC, some values of $D_{m}$ estimated from the ARRC profiler data are two to three times larger than those from KOUN. Errors in the estimation of DSD parameters from profiler data can occur if the ambient vertical wind is not properly accounted for (Kanofsky and Chilson, 2008). However, an overestimation of $D_{m}$ is expected for unaccounted for upward wind velocity. For the period in question, a downward velocity has been observed (Teshiba et al., 2009). It is also possible that values of $D_{m}$ from KOUN are underestimated. Currently, the cause of the sharp difference is not known.

Bearing the above discrepancies in mind and proceeding with caution, it is still possible to draw some conclusions from the results shown in Figs. 4 and 5. In the convective regime, values of $D_{m}$ are typically greater than $3 \mathrm{~mm}$ in the convective cores and near $1 \mathrm{~mm}$ in the downdrafts, suggesting rapid drop growth and large-drop spectra in the convective regime while the downdrafts contain concentrations of smaller drops. This is consistent with the plot of $D_{m}$ in Fig. 3, which indicates a rapid decrease in the massweighted mean diameter in the wake of the convection (after $\sim 11: 30$ UTC). The values of $D_{m}$ here are consistent with those presented by Uijlenhoet et al. (2003) and Maki et al. (2001) for squall lines observed in the United States and Australia, respectively. 

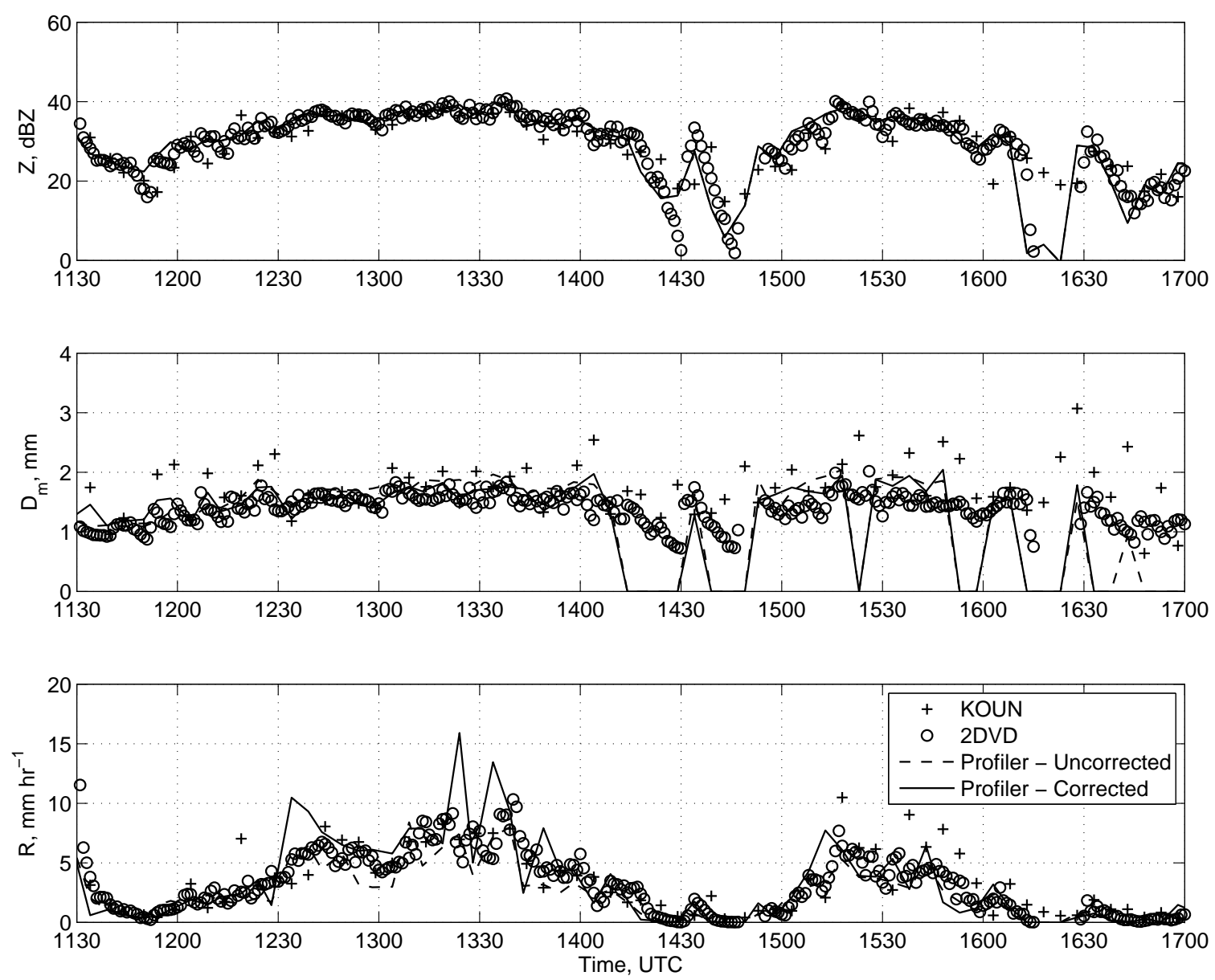

Fig. 6. Time history of $Z, D_{m}$, and $R$ from 13 July 2007 rain event. The 2DVD data were collected at the surface and the radar data correspond to a height of $600 \mathrm{~m}$ a.g.l.

In the transition zone, $D_{m}$ values of approximately $1 \mathrm{~mm}$ indicate small drop spectra, while in a convective downdraft following the transition zone, characteristic $D_{m}$ values increase to 2.5 to $3 \mathrm{~mm}$. It is likely that the settling of remnant hydrometeors from the convective region produces the larger drops that are observed in this case. The change in $D_{m}$ is similar in concept to the change in $N_{0}$ as the spectra changes from small-drop spectra in the transition region to intermediate-size spectra in the downdraft (Waldvogel, 1974).

In the stratiform region of the MCS, the fallstreaks of increased $Z_{D R}$ observed in Fig. 2 are associated with larger $D_{m}$ values and, by extension, large-drop spectra. However, there is not an appreciable change in the mass-weighted mean diameter apparent in Fig. 3. These features indicate the presence of weak embedded convection in the stratiform regime, which also produces the enhanced $Z_{H}$ above the melting layer observed in Fig. 2.

\section{Case study - 13 July 2007}

A second mature squall line event occuring early in the morning of 13 July 2007 provided additonal opportunity to study rain microphysics in much the same way as the 11 March 2007 case. During this event, KOUN collected polarimetric data in standard plan-position indicator (PPI) mode as opposed to the RHI mode which was employed on 11 March, but due to a network failure a substantial number of tilts are missing before 10:00 UTC. However, the ARRC profiler and 2DVD provided continuous data for the duration of the event.

A total of $42 \mathrm{~mm}$ of precipitation was measured by the Washington Oklahoma Mesonet installation during the passage of the system. This squall line event adhered more closely to the "classic" MCS morphology, with an unbroken line of leading convection, strong transition zone, and extensive trailing stratiform precipitation. By contrast, the leading convection of the 11 March event was slightly more cellular in appearance and the system was attended by a midlevel mesoscale convective vortex that is often observed in asymmetric squall lines. 

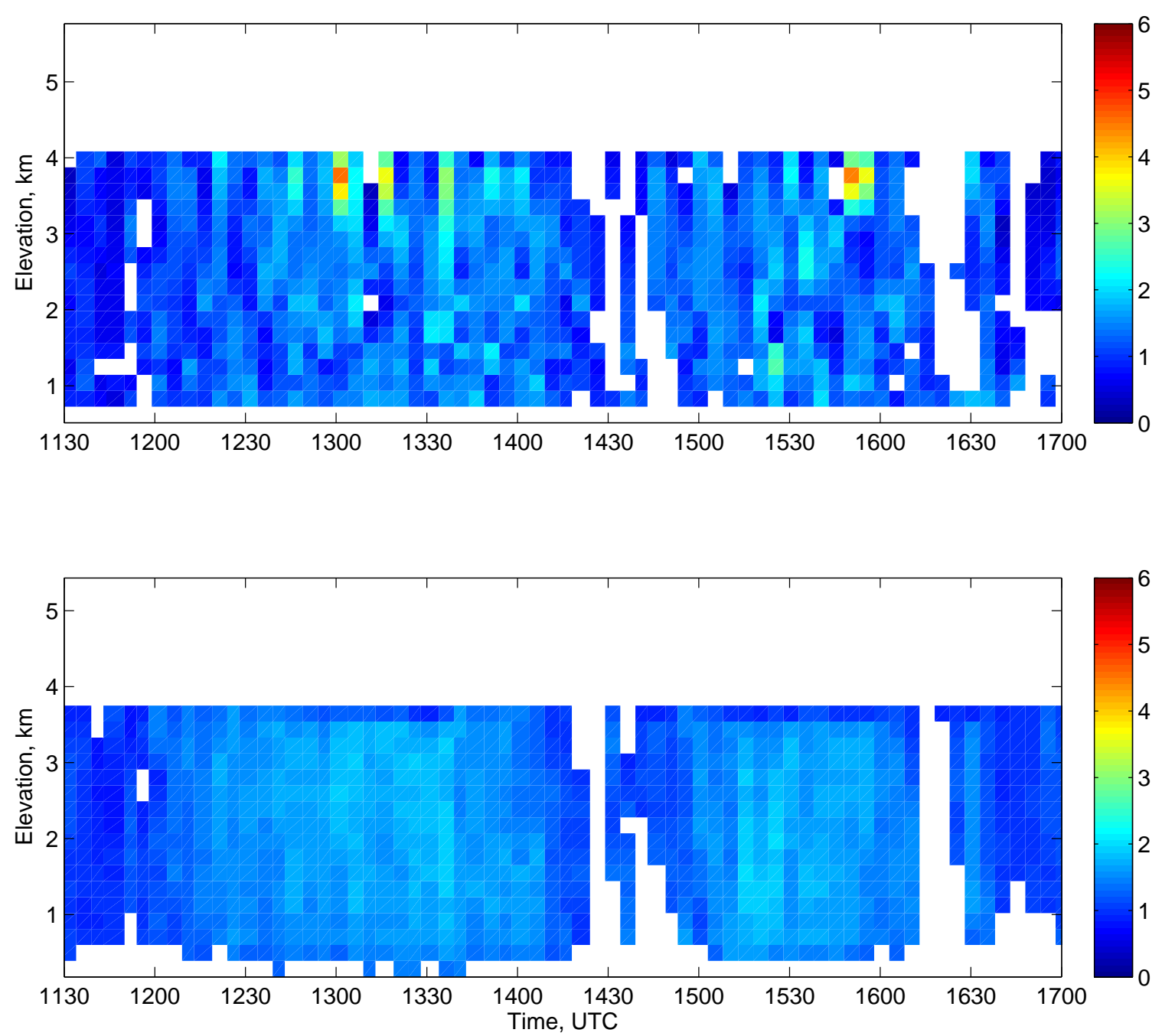

Fig. 7. RTI plots of $D_{m}$ for an exponential DSD retrieved from KOUN (upper panel) and the ARRC profiler (lower panel) during 13 July 2007 rain event. Units are in mm. Data above the melting layer are not presented.

\subsection{DSD parameters}

The time histories of radar reflectivity factor $Z$, massweighted mean diameter $D_{m}$ and rainfall rate $R$ is presented for the 13 July event in Fig. 6. Data from all three instruments are presented to facilitate intercomparison, and the retrieved DSDs from the ARRC profiler with and without the vertical velocity correction applied are plotted to show improvement in the retrievals. As in Fig. 3, DSD data from the profiler and KOUN are from the third gate above ground level $(\sim 600 \mathrm{~m})$ and the 2DVD data are recorded at the surface.

The upper panel of Fig. 6 indicates that the radar reflectivity factor is nearly the same for the 13 July data and the stratiform precipitation portion of the 11 March squall line, with observed values falling between 35 and $40 \mathrm{dBZ}$. A lull in precipitation is clearly evident as a period of reflectivity factor values below $20 \mathrm{dBZ}$ between 14:30 UTC and 15:00 UTC and rainfall rate values of $0 \mathrm{~mm} \mathrm{~h}^{-1}$ (lower panel of Fig. 6). It is notable that the $Z$ values agree well for the majority of the event as the calibration constant used for the 11 March 2007 case was also appropriate for this event.

Table 4 lists the rainfall accumulations recorded during the interval 11:00 UTC-16:00 UTC 13 July 2007. Overall, rainrates and associated accumulations were lower for this event than the 11 March event as most of the rain was stratiform in nature. Only the 2DVD overestimated the rainfall accumulation in this case, and it was only by $1.4 \mathrm{~mm}$. All the other instruments produced slight underestimates of the rainfall accumulation, but the results agree well nonetheless.

Figure 7 displays time-height plots of the mass-weighted mean diameter for a fitted exponential DSD, and Fig. 8 shows a time history at 1,2 , and $3 \mathrm{~km}$ a.g.l. Compared to the stratiform region of the 11 March MCS, both the profiler and KOUN indicate $D_{m}$ values between $1 \mathrm{~mm}$ and $2 \mathrm{~mm}$ and are 

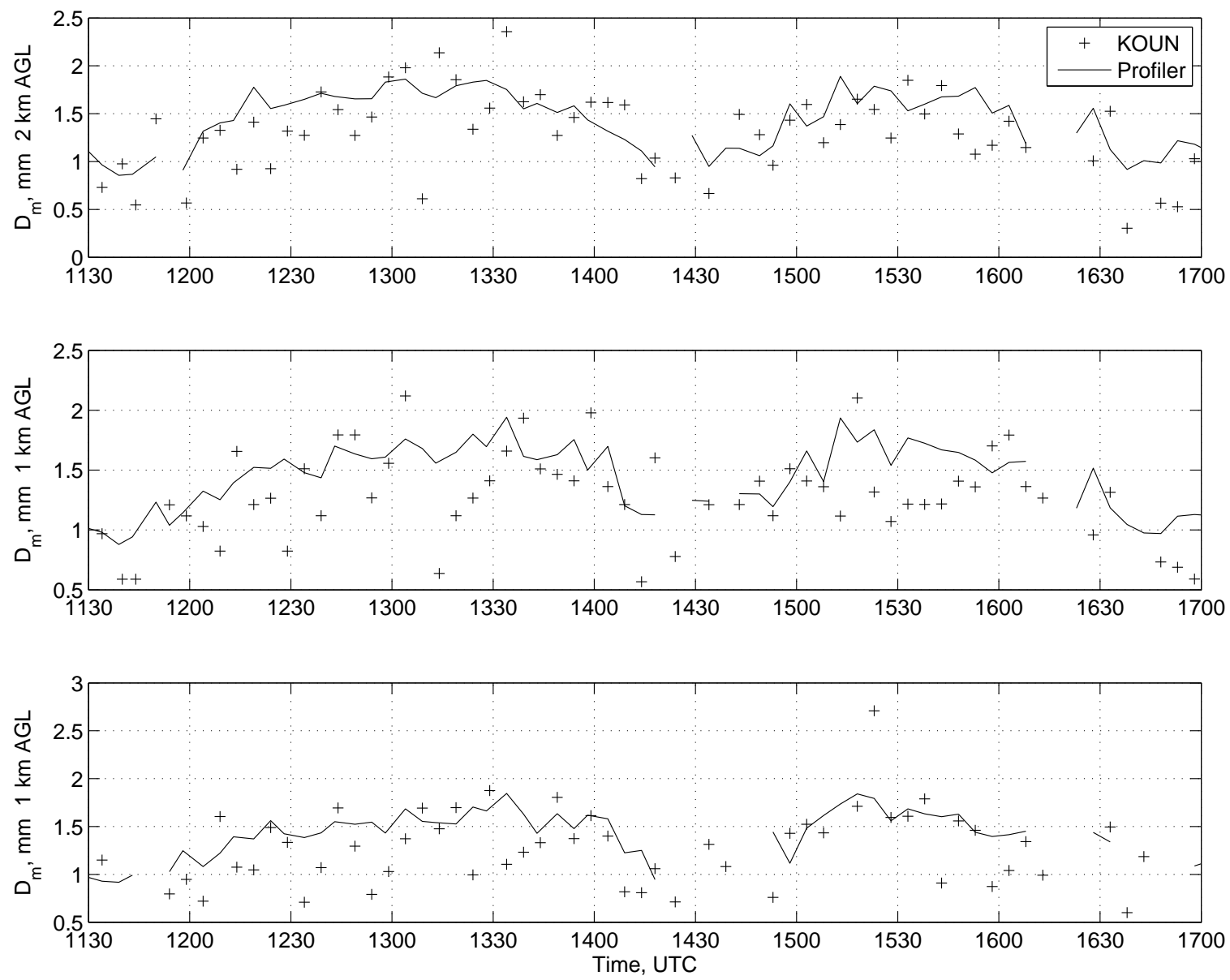

Fig. 8. Time history plots of $D_{m}$ for an exponential DSD retrieved from KOUN during 13 July 2007 rain event at $3 \mathrm{~km}$ a.g.l. (upper panel), $2 \mathrm{~km}$ a.g.l. (middle panel) and $1 \mathrm{~km}$ a.g.l. (lower panel).

Table 4. Total rainfall accumulations for the 13 July 2007 event.

\begin{tabular}{lc}
\hline Instrument & Total rainfall \\
\hline Oklahoma mesonet & $14.48 \mathrm{~mm}$ \\
KOUN & $12.49 \mathrm{~mm}$ \\
Profiler - uncorrected & $10.1 \mathrm{~mm}$ \\
Profiler - corrected & $13.97 \mathrm{~mm}$ \\
2DVD & $15.88 \mathrm{~mm}$ \\
\hline
\end{tabular}

consistent with the small-drop (i.e., low $Z_{D R}$ ) regions of the stratiform rainfall. The extreme values at the beginning and end of the event are associated with spurious retrieval in regions of low signal-to-noise ratio.

\section{Summary and discussion}

In this paper, we present two case studies of continental squall lines, demonstrating the utility of polarimetric radar data to improve wind profiler-based microphysics retrieval, and assess the degree of error in both polarimetric and wind profiler retrievals compared to a video disdrometer. Data were collected during the spring and summer of 2007, and the behavior of the events chosen for this analysis is believed to be representative of the types of systems that frequently impact central Oklahoma during these periods. The present study stands as an indirect validation of the vertical velocity retrieval method outlined by Teshiba et al. (2009). First, estimates of the vertical air motion obtained using the procedure described in Teshiba et al. (2009) are calculated. The effects of the updrafts and downdrafts are then removed from the observed Doppler spectra using a vertically pointing UHF wind profiler. The resulting Doppler spectra correspond to the terminal fall speeds of the rain drops. Applying the correction improved the microphysics retrieval during convective rain.

Tables 5 and 6 display the bias of each dataset relative to the 2DVD for the parameters $Z, D_{m}$, and $R$. The values shown are averages calculated over the observation times. For the 11 March rain event, the data shown in the table correspond to a sampling interval of about three and a half hours 
Table 5. Bias of retrieved parameters relative to 2DVD observations from 11 March squall line.

\begin{tabular}{cccc}
\hline Parameter (units) & KOUN & Profiler - uncorrected & Profiler - corrected \\
\hline$Z(\mathrm{dBZ})$ & 0.1074 & -0.3588 & -0.3588 \\
$D_{m}(\mathrm{~mm})$ & -0.0912 & -0.209 & -0.0631 \\
$R\left(\mathrm{~mm} \mathrm{~h}^{-1}\right.$ & -2.3240 & -4.2715 & -3.2116 \\
\hline
\end{tabular}

Table 6. Bias of retrieved parameters relative to 2DVD observations from 13 July squall line.

\begin{tabular}{cccc}
\hline Parameter (units) & KOUN & Profiler - uncorrected & Profiler - corrected \\
\hline$Z(\mathrm{dBZ})$ & 0.7971 & 0.6012 & 0.6012 \\
$D_{m}(\mathrm{~mm})$ & 0.5460 & -0.2931 & -0.2462 \\
$R\left(\mathrm{~mm} \mathrm{~h}^{-1}\right.$ & 0.3918 & 0.3210 & -0.4218 \\
\hline
\end{tabular}

(11:15-14:48 UTC). For the July 13 case, the sampling interval was four hours long (11:00-16:00 UTC).

During the 11 March event, all three datasets exhibit a slight low bias in the rainfall rates, which can be seen clearly in Fig. 3, as there are two periods in the stratiform precipitation regime where both radars underestimate $R$ compared to the 2DVD. In the convective regime, the better agreement between KOUN and the 2DVD leads to the overall improvement in agreement relative to the wind profiler, which even with the vertical velocity correction still significantly underestimated the rainfall rate during this brief window. However, this may serve as a testament to its accuracy in the stratiform precipitation region, as the wind profiler performs best when the vertical air motion is negligible. Additionally, there is no way for the vertical velocity retrieval method to account for bimodal spectra, which introduces some error in the mean radial velocity estimate from the KOUN DSD data. A significant improvement in the retrieved mass-weighted mean diameter $(69.8 \%)$ was observed for the wind profiler data when the vertical velocity correction was introduced, the majority of which occured in the first half of the event, prior to $\sim 13: 30$ UTC.

During the 13 July event, errors from KOUN are greater than those seen on 11 March, perhaps in part as a result of the interpolation necessary to reconstruct 26 height gates (to match the profiler) from a volume coverage pattern of 14 tilts. From Table 6, it is apparent that KOUN and the UHF profiler performed rather similarly in this case, but it must be noted that stratiform rain was the dominant mode of precipitation observed on July 13, so it is expected that neither instrument would have an inherent advantage over the other. During this event, KOUN overestimated the mass-weighted mean diameter by $\sim 0.5 \mathrm{~mm}$, while the wind profiler has underestimated by $\sim 0.25 \mathrm{~mm}$, with only a slight improvement observed with the vertical velocity correction. A confounding result appears in the retrieved rainfall rates, as the uncorrected wind profiler data overestimate the rainfall, while the corrected data underestimate it, and to a slightly greater degree.

Acknowledgements. Topical Editor F. D'Andrea thanks two anonymous referees for their help in evaluating this paper.

\section{References}

Balsley, B. B. and Gage, K.: On the use of radars for operational profiling, B. Am. Meteorol. Soc., 63, 1009-1018, 1982.

Battan, L. J.: Radar Observation of the Atmosphere, Univ. of Chicago Press, 1973.

Brandes, E., Zhang, G., and Vivekanandan, J.: Drop Size Distribution Retrieval with Polarimetric Radar, J. Appl. Meteor., 43, 461-475, 2004.

Brandes, E. A., Zhang, G., and Vivekanandan, J.: Experiments in Rainfall Estimation with a Polarimetric Radar in a Subtropical Environment, J. Appl. Meteor., 41, 674-685, 2002.

Cao, Q., Zhang, G., Brandes, E., Schuur, T., Ryzhkov, A., and Ikeda, K.: Analysis of Video Disdrometer and Polarimetric Radar Data to Characterize Rain Microphysics in Oklahoma, J. Appl. Meteor. Climat., 47, 2238-2255, 2007.

Carter, D. A., Gage, K. S., Ecklund, W. L., Angevine, W. M., Johnston, P. E., Riddle, A. C., Wilson, J., and Williams, C. R.: Developments in UHF Lower Tropospheric Wind Profiling at NOAA's Aeronomy Laboratory, Radio Sci., 17, 257-278, 1995.

Chilson, P. B., Zhang, G., Schuur, T., Kanofsky, L. M., Teshiba, M. S., Cao, Q., Every, M. V., and Ciach, G.: Coordinated In-Situ and Remote Sensing Precipitation Measurements at the Kessler Farm Field Laboratory in Central Oklahoma, in: Preprints - 33rd International AMS Radar Conference, Sydney, Australia, American Meteorological Society, Boston, MA, 2007.

Cifelli, R., Williams, C. R., Rajopadhyaya, D. K., Avery, S. K., Gage, K. S., and May, P. T.: Drop-Size Distribution Characteristics of Precipitation in Tropical Showers, J. Appl. Meteor., 39, 760-777, 2000.

Doviak, R. J. and Zrnic, D. S.: Doppler Radar and Weather Observations, Dover, 1993. 
Doviak, R. J., Bringi, V. N., Ryzhkov, A. V., Zahrai, A., and Zrnic, D. S.: Considerations for Polarimetric Upgrades to Operational WSR-88D Radars, J. Atmos. Ocean. Tech., 17, 257-278, 2000.

Foote, G. B. and duToit, P. S.: Terminal Velocity of Raindrops Aloft, J. Appl. Meteor., 8, 249-253, 1969.

Gage, K. S., Williams, C. R., Johnston, P. E., Ecklund, W. L., Cifelli, R., Tokay, A., and Carter, D. A.: Doppler Radar Profilers as Calibration Tools for Scanning Radars, J. Appl. Meteor, 12, 2209-2222, 2000.

Gans, R.: Über die Form ultramikroskopischer Goldteilchen, Ann. Phys., 342, 881-900, 1912.

Gorgucci, E., Chandrasekar, V., and Baldini, L.: Microphysical Retrievals from Dual-Polarization Radar Measurements at X-Band, J. Atmos. Ocean. Tech., 25, 729=741, 2008.

Houze, R. A.: Cloud Dynamics, Academic Press, 1993.

Houze, R. A. and Rappaport, E. N.: Air Motions and Precipitation Structure of an Early Summer Squall Line Over the Eastern Tropical Atlantic, J. Atmos. Sci., 41, 553-574, 1984.

Illingworth, A. J. and Thompson, R. J.: The Estimation of Rain Rates with Modern Polarization Radar, in: Preprints - 32nd Conference on Radar Meteorology, American Meteorological Society, Boston, MA, 2005.

Kanofsky, L. M. and Chilson, P. B.: An Analysis of Errors in Drop Size Distribution Retrievals and Rain Bulk Parmameters with a UHF Wind Profiling Radar and a Two-Dimensional Video Disdrometer, J. Atmos. Ocean. Tech., 25, 2282-2292, 2008.

Kruger, A. and Krajewski, W. F.: Two-Dimensional Video Disdrometer: A Technical Description, J. Atmos. Ocean. Tech., 19, 602-617, 2002.

Kumjian, M. and Ryzhkov, A. V.: Polarimetric Signatures in Supercell Thunderstorms, J. Appl. Meteor., 47, 1940-1961, 2008.

Laws, J. O. and Parsons, D. A.: The Relation of Raindrop-Size to Intensity, Trans. Amer. Geophys. Union, 24, 452-460, 1943.

Maki, M., Keenan, T., Sasaki, Y., and Nakamura, K.: Characteristics of Raindrop Size Distribution in Tropical Continental Squall Lines Observed in Darwin, Australia, J. Appl. Meteor, 40, 1393$1412,2001$.

Morris, M. P.: Microphysical Properties of Central Oklahoma Squall Lines Revealed by Combined Profiling and Polarimetric Radar, M.S. Thesis, University of Oklahoma, 2008.

Morris, M. P., Chilson, P. B., Ryzhkov, A. V., Schuur, T. J., Teshiba, M. S., Zhang, G., Cao, Q., Palmer, R. D., and Kanofsky, L. M.: An Inter-Comparison of Raindrop Size Distributions Retrieved from Polarimetric Radar Parameters, in: Preprints - AMS Symposium on Recent Developments in Atmospheric Applications of Radar and Lidar, American Meteorological Society, Boston, MA, 2008.

Pruppacher, H. R. and Beard, K. V.: A Wind Tunnel Investigation of the Internal Circulation and Shape of Water Drops Falling at Terminal Velocity in Air, Quart. J. Royal Met. Soc., 96, 247-256, 1970.

Pruppacher, H. R. and Klett, J. D.: Microphysics of Clouds and Precipitation, Springer, 1997.

Rogers, R. R.: Doppler Radar Investigation of Hawaiian Rain, Tellus, 19, 432-455, 1967.

Ryzhkov, A. V., Schuur, T. J., Burgess, D. W., Heinselman, P. L., Giangrande, S. E., and Zrnic, D. S.: The Joint Polarization Experiment: Polarimetric Rainfall Measurements and Hydrometeor Classification, B. Am. Meteorol. Soc., 86, 809-824, 2005a.
Ryzhkov, A. V., Schuur, T. J., Burgess, D. W., and Zrnic, D. S.: Polarimetric Tornado Detection, J. Appl. Meteor., 44, 557-570, 2005b.

Sachidananda, M. and Zrnic, D.: Ground Clutter Filtering DualPolarized, Staggered PRT Sequences, J. Atmos. Ocean. Tech., 23, 1114-1130, 2006.

Saffle, R. E., Cate, G. S., and Istok, M.: NEXRAD Product Improvement - Update 2007, in: Preprints - 23rd Conference on IIPS, San Antonio, Texas, American Meteorological Society, Boston, MA, 2007.

Schafer, R., Avery, S. K., May, P. T., Rajopadhyaya, D., and Williams, C.: Estimation of Rainfall Drop Size Distributions from Dual Frequency Wind Profiler Spectra Using Deconvolution and a Non-Linear Least Squares Fitting Technique, J. Atmos. Ocean. Tech., 19, 864-874, 2002.

Seliga, T. and Bringi, V. N.: Differential Reflectivity and Differential Phase Shift: Applications in Radar Meteorology, Radio Sci., 13, 271-275, 1978.

Seliga, T. A. and Bringi, V. N.: Potential use of Radar Differential Reflectivity Measurements at Orthogonal Polarizations for Measuring Precipitation, J. Appl. Meteor., 15, 69-76, 1976.

Smull, B. F. and Houze, R. A.: Dual-Doppler Analysis of a Midlatitude Squall Line with a Trailing Region of Stratiform Precipitation, J. Atmos. Sci., 44, 2128-2148, 1987.

Tennekes, H. and Lumley, J. L.: A First Course in Turbulence, MIT Press, 1973.

Teshiba, M. S., Chilson, P. B., Ryzhkov, A. V., Schuur, T. J., and Palmer, R. D.: A Combined Wind Profiler and Polarimetric Weather Radar Method for the Investigation of Precipitation and Vertical Velocities, J. Atmos. Ocean. Tech., 26, 1940-1954, 2009.

Tokay, A. and Short, D. A.: Evidence from Tropical Raindrop Spectra of the Origin of Rain from Stratiform versus Convective Clouds, J. Appl. Meteor., 35, 355-371, 1996.

Uijlenhoet, R., Steiner, M., and Smith, J. A.: Variability of Raindrop Size Distributions in a Squall Line and Implications for Radar Rainfall Estimation, J. Hydrometeorology, 4, 43-61, 2003.

Wakasugi, K., Mitutani, A., Matsuo, M., Fukao, S., and Kato, S.: A Direct Method for Deriving Drop-Size Distributions and Vertical Air Motion from VHF Doppler Radar Spectra, J. Atmos. Ocean. Tech., 3, 623-629, 1986.

Waldvogel, A.: The $N_{0}$ Jump of Raindrop Spectra, J. Atmos. Sci., 31, 1067-1078, 1974.

Zhang, G., Vivekanandan, J., and Brandes, E.: A Method for Estimating Rain Rate and Drop Size Distribution from Polarimetric Radar Measurements, IEEE Trans. Geosci. Remote Sens., 39, 830-841, 2001.

Zhang, G., Sun, J., and Brandes, E.: Improving Parameterization of Rain Microphysics with Disdrometer and Radar Observations, J. Atmos. Oceanic Tech., 63, 1273-1282, 2006.

Zhang, G., Xue, M., Cao, Q., and Dawson, D.: Diagnosing the Intercept Parameter for Exponential Raindrop Size Distribution Based on Video Disdrometer Obserrvations: Model Development, J. Appl. Meteor. Climat., 47, 2983-2992, 2008. 